\title{
The effect of iron on Streptococcus mutans biofilm and on enamel demineralization
}

\section{Cecília Cláudia Costa Ribeiro(a) Renzo Alberto Ccahuana- Vásquez $^{(\mathbf{b})}$ \\ Cadidja Dayane Sousa do Carmo(a) \\ Cláudia Maria Coêlho Alves ${ }^{(a)}$ \\ Tarcísio Jorge Leitão(a) \\ Lisandra Rocha Vidotti(c) \\ Jaime Aparecido Cury ${ }^{(b)}$}

(a) School of Dentistry, Federal University of Maranhão, São Luís, MA, Brazil.

(b) Piracicaba Dental School, Universidade de Campinas - UNICAMP, Piracicaba, SP, Brazil.

(c) Post-graduation Program for Maternal Child Health, Federal University of Maranhão, São Luís, MA, Brazil.

\begin{abstract}
Iron (Fe) may have an anticaries effect by specific inhibition of glycosyltransferase (GTF) enzymes of Streptococcus mutans, but this hypothesis has not yet been clarified. In this study, S. mutans biofilms were formed on blocks of bovine dental enamel of a predetermined surface hardness $(\mathrm{SH})$. These biofilms were exposed eight times/day to $10 \%$ sucrose, and two times/day they were subjected to one of the following treatments: $\mathrm{G} 1,0.9 \% \mathrm{NaCl}$ as a negative control; G2, $0.12 \%$ chlorhexidine digluconate $(\mathrm{CHX})$ as a positive antibacterial control; $\mathrm{G} 3,0.05 \%$ $\mathrm{NaF}$ (225 ppm F) as a positive anticaries control; G4, G5, and G6, ferrous sulfate $\left(\mathrm{Fe}^{2+}\right)$ at concentrations of $1.0,10.0$, and $100.0 \mu \mathrm{g} \mathrm{Fe} / \mathrm{mL}$, respectively. The experiment was performed in triplicate and was repeated three times $(\mathrm{n}=9)$. The $\mathrm{pH}$ of the culture medium was determined every $24 \mathrm{~h}$ as an indicator of the biofilm's acidogenicity. The biofilm formed on each block was collected for determination of the viable bacteria and concentration of extracellular polysaccharides (EPS). Enamel SH was again determined and the percentage of $\mathrm{SH}$ loss (\%SHL) was calculated as an indicator of demineralization. Iron treatment reduced the number of viable bacteria formed in the $S$. mutans biofilm $(\mathrm{p}=0.04)$, in a dosedependent manner, and also reduced the enamel's \%SHL $(\mathrm{p}=0.005)$. At $100 \mu \mathrm{g} / \mathrm{mL}$, Fe reduced enamel demineralization as effectively as CHX and $\mathrm{NaF}(\mathrm{p}<0.05)$, but it did not inhibit EPS production. In conclusion, the data suggest that the anticaries mechanism of action of Fe may not involve the oxidative inhibition of GTFs.
\end{abstract}

Descriptors: Iron; Biofilms; Dental Enamel; Demineralization.

\section{Introduction}

Dental caries is a multifactorial, biofilm-sugar-dependent disease. ${ }^{1}$ While $S$. mutans is considered one of the most cariogenic bacteria present in dental biofilms, ${ }^{2}$ sucrose is considered the most cariogenic dietary sugar ${ }^{3}$ and iron $(\mathrm{Fe})$ may have an anticaries effect by interference with both these factors.

Iron is an essential chemical element for humans, ${ }^{4}$ and experiments using animal caries models ${ }^{5,6}$ and an in situ model $^{7}$ have suggested that it can also have anticaries potential. However, the mechanism by which Fe exercises its antibacterial effect, thereby contributing to the control of caries, remains under discussion.

Iron $(\mathrm{Fe})$ has an antibacterial effect not only in terms of killing StrepAccepted for publication on May 09, 2012
Received for publication on Jan 03, 2012

\section{Corresponding Author:}

Jaime Aparecido Cury

E-mail: jcury@fop.unicamp.br 
tococcus mutans cells ${ }^{8}$ but also by interfering with the ability of this bacteria to form biofilm. ${ }^{9}$ In addition, it has been shown that Fe interferes with the implantation of streptococcus in the oral cavity of rats. ${ }^{5,6,10}$ Furthermore, it has been shown in situ that the dental biofilm formed in humans exposed to $\mathrm{Fe}$ has a lower $S$. mutans count. ${ }^{7}$

In terms of its mechanism of action, ${ }^{8}$ it has been suggested that $\mathrm{Fe}$ may have an anticaries effect due to its ability to inhibit the F-ATPase of $S$. mutans. Consequently, Fe may affect the acidogenicity and aciduricity of $S$. mutans. On the other hand, by interfering with sucrose metabolism, Fe may reduce the production of extracellular polysaccharides (EPS), which are considered virulence factors of $S$. mutans. ${ }^{11}$ Moreover, it has been shown that $\mathrm{Fe}$ inhibits glycotransferase (GTF) enzymes produced by $S$. mutans in vitro ${ }^{12}$ via an oxidative mechanism involving a Fenton-type reaction. ${ }^{13}$ However, Fe at a concentration of $70 \mu \mathrm{g} / \mathrm{mL}(1.2 \mathrm{mM})$ has shown no in situ effect either on the acidogenicity of dental biofilm or in terms of reducing the quantity of EPS in a biofilm exposed to $10 \%$ sucrose, ${ }^{7}$ thus suggesting the need for further studies on the mechanism of action of the anticaries effect of Fe.

Therefore, the objective of this work was to study the anticaries mechanism of $\mathrm{Fe}$ using a $S$. mutans biofilm validated model, which allows not only evaluation of the antimicrobial effect of the substances on bacteria organized in the form of a biofilm but also the consequent enamel demineralization, as an indicator of the anticaries effect. Also, evaluation of the mechanism of action of Fe on GTF enzymes or on EPS production using this biofilm model has advantages compared to in vitro studies using isolated GTF or in situ studies with dental biofilm because the effect was tested, respectively, on the enzymes in their native cellular state, and EPS was produced only by $S$. mutans and not by the other biofilm streptococci.

\section{Methodology Experimental design}

The experiment was performed in triplicate with three repetitions $(\mathrm{n}=9$ ). Fifty-four blocks of bovine dental enamel, of a predetermined surface hard- ness $(\mathrm{SH})$, were randomly divided into the following treatment groups:

- $\mathrm{G} 1,0.9 \% \mathrm{NaCl}$, as a negative control;

- G2, $0.12 \%$ chlorhexidine digluconate (CHX), as a positive antibacterial control;

- G3, $0.05 \% \mathrm{NaF}$ (225 ppm F) as a positive anticaries control;

- $\mathrm{G} 4,1.0 \mu \mathrm{g} / \mathrm{mL}$ Fe $(0.018 \mathrm{mM})$;

- G5, $10.0 \mu \mathrm{g} / \mathrm{mL}$ Fe $(0.18 \mathrm{mM})$; and

- $\mathrm{G} 6,100.0 \mu \mathrm{g} / \mathrm{mL}$ Fe $(1.8 \mathrm{mM})$.

S. mutans biofilms were formed on bovine dental blocks suspended vertically in culture medium ${ }^{14}$ using a validated model, which was previously shown to have a dose-dependent response for evaluating the effect of antimicrobial substances on biofilm formation and on enamel demineralization. ${ }^{15}$ The biofilms were exposed eight times/day for $2.5 \mathrm{~min}$ in a $10 \%$ sucrose solution; after the biofilms were allowed to grow for $48 \mathrm{~h}$, they were treated two times/ day for 1 min according to the treatment groups described above. The $\mathrm{pH}$ of the culture medium was determined every $24 \mathrm{~h}$ as an indicator of the biofilm's acidogenicity. After $120 \mathrm{~h}$ of growth, the biofilm formed on each block was collected so as to determine the number of viable bacteria, biomass (dry weight and proteins), and composition of the soluble EPS (SEPS) and insoluble EPS (IEPS). Enamel demineralization was quantified based on the percentage of surface hardness loss (\%SHL).

\section{Preparation of enamel blocks}

One hundred and fifty blocks of enamel $(4 \times 7 \times 1 \mathrm{~mm})$ were prepared from dental crowns of bovine incisors as described, ${ }^{15}$ and 54 blocks with a hardness of between 313.8 and $331.7 \mathrm{~kg} / \mathrm{mm}^{2}$ were selected; these were then randomly divided into six groups of nine blocks each to receive the treatments described above.

The blocks were sterilized in an autoclave ${ }^{15}$ and pre-treated with clarified human saliva for the formation of salivary acquired pellicles. ${ }^{14}$

\section{S. mutans biofilm formation}

Inoculation for biofilm formation was prepared using an 18 h culture of $S$. mutans UA 159 cultivat- 
ed in ultrafiltered culture media containing tryptone and yeast extract (UTYEB) supplemented with $1 \%$ glucose. Next $0.1 \mathrm{~mL}$ of the culture was diluted in $50 \mathrm{~mL}$ of UTYEB containing $1 \%$ sucrose.${ }^{14}$ Aliquots $(2 \mathrm{~mL})$ of this inoculation were transferred to 24 well culture plates in which enamel blocks were individually suspended. The plates were incubated in $10 \% \mathrm{CO}_{2}$ for $8 \mathrm{~h}$ at $37^{\circ} \mathrm{C} .{ }^{15}$

After $8 \mathrm{~h}$, the biofilms were transferred to plates containing $2.0 \mathrm{~mL}$ of UTYEB and $0.1 \mathrm{mM}$ glucose (the basal concentration of glucose in saliva) and incubated for another $16 \mathrm{~h}$. On the following day, $24 \mathrm{~h}$ after the start of the experiment, the biofilms were transferred to fresh media and then treated with $10 \%$ sucrose for $2.5 \mathrm{~min}$ eight times/day at predetermined times (8:00, 9:30, 11:00, 12:30, 14:00, 15:30, 17:00, and 18:30). These first two days were used for bacterial adhesion and to allow the initial formation of the biofilm as described previously. ${ }^{15}$

After the biofilm had grown for $48 \mathrm{~h}$, the treatments (G1-G6) began, with the eight exposures to sucrose maintained. The culture medium was changed every $24 \mathrm{~h}$ on the morning of each day.

\section{Treatments}

The treatments were performed for $1 \mathrm{~min}$ two times/day, before the first and last exposure to sucrose. After each treatment, the biofilms were washed three times in $0.9 \% \mathrm{NaCl}$. The CHX (Sigma, Steinheim, Germany) solution was prepared in sterile distilled water. The $0.05 \% \mathrm{NaF}$ solution was prepared in distilled water and sterilized by autoclaving. The Fe solutions at concentrations from 1 to $100 \mu \mathrm{g} / \mathrm{mL}$ were prepared from $\mathrm{FeSO}_{4} \cdot 7 \mathrm{H}_{2} \mathrm{O}$ in distilled water and sterilized by filtration.

\section{Analyses}

On the morning of the sixth day, the dental blocks were washed three times in $0.9 \% \mathrm{NaCl}$ and individually transferred to microcentrifuge tubes containing $1 \mathrm{~mL}$ of $0.9 \% \mathrm{NaCl}$, with the attached biofilms removed by sonication. ${ }^{15}$ The enamel blocks were removed for analysis of hardness, and aliquots from the suspension were withdrawn to determine dry weight and the amounts of total proteins, viable bacteria, and polysaccharides.
The biofilm dry weight was determined from $200 \mu \mathrm{L}$ of the suspension. ${ }^{14}$ As a biomass indicator, alkali-soluble proteins were determined using $50 \mu \mathrm{L}$ of the suspension; and the viable bacteria were determined from $100 \mu \mathrm{L}$ of the suspension. The results were expressed in total proteins/mg of the biofilm dry weight and CFU/mg of the biofilm dry weight, respectively. ${ }^{15}$ SEPS and IEPS were determined following published procedures. ${ }^{16}$

To evaluate enamel demineralization, the $\mathrm{SH}$ of the enamel blocks was again determined. One row of three adjacent indentations spaced $100 \mu \mathrm{m}$ apart was made $100 \mu \mathrm{m}$ from the three baseline measurements. The mean values of the three baseline indentations and the three measurements after treatments were then averaged and the \% SHL was calculated as follows:

$$
\begin{aligned}
& \% \text { SHL }=(\text { baseline } \mathrm{SH}-\mathrm{SH} \text { after treatment }) \\
& \times 100 / \text { baseline } \mathrm{SH} .{ }^{17}
\end{aligned}
$$

\section{Statistical analysis}

The blocks were considered as experimental units $(\mathrm{n}=9)$. After checking the data normality, the variables concerning viable bacteria and the demineralization of dental enamel showed non-normal distribution, so they were log transformed. ${ }^{18}$

To compare the treatments, an analysis of variance (ANOVA) was performed, followed by Tukey's test. For variables that showed significant difference between any one of the treatments and the negative control, a linear regression was performed to evaluate the effect of the Fe concentration (i.e., dose-response curve). SAS software was used for all analyses, and the significance threshold was $5 \%$.

\section{Results}

As shown in Figure 1, CHX was able to inhibit the ability of the biofilm to ferment sucrose $(\mathrm{p}<0.05)$. In terms of the biofilm formed, only CHX was able to significantly reduce $(\mathrm{p}<0.05)$ the biomass and IEPS (Table 1), in comparison to the negative control.

In terms of the effect on the enamel, Fe $(100 \mu \mathrm{g} /$ $\mathrm{mL}$ ) reduced demineralization, as reflected by the 
Figure 1 - Mean $\mathrm{pH}$ values (SD;

$\mathrm{n}=9$ ) of the culture medium after $48 \mathrm{~h}$ of biofilm growth in the absence of treatments and at each $24 \mathrm{~h}$ after beginning the treatments $(72,96$, and $120 \mathrm{~h}$ data).

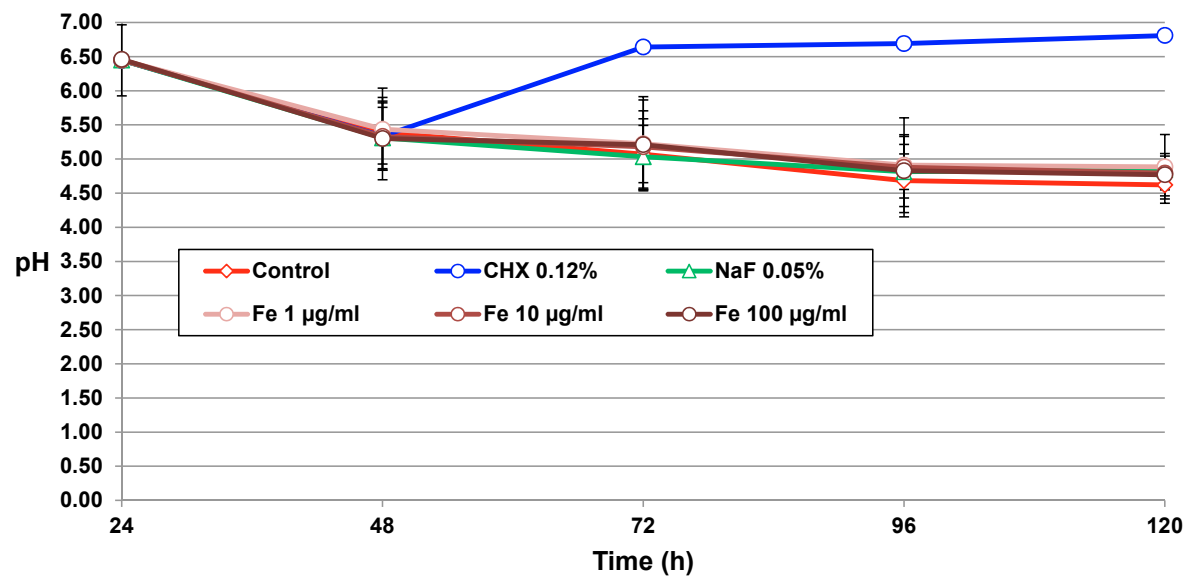

Table 1 - Biofilm weight and quantities of proteins, viable bacteria, and EPS according to the treatments (mean \pm SD; $n=9)$.

\begin{tabular}{|c|c|c|c|c|c|}
\hline \multirow{2}{*}{ Treatment } & \multirow{2}{*}{$\begin{array}{c}\text { Biofilm } \\
\text { (mg of dry weight) }\end{array}$} & \multirow{2}{*}{$\begin{array}{l}\text { Alkali-soluble proteins } \\
\text { ( } \mu \mathrm{g} / \mathrm{mg} \text { of dry weight) }\end{array}$} & \multirow{2}{*}{$\begin{array}{c}\text { Viable bacteria } \\
\left(\mathrm{CFU} / \mathrm{mg} \text { of dry weight } \times 10^{5}\right)\end{array}$} & \multicolumn{2}{|c|}{ EPS ( $\mu \mathrm{g} / \mathrm{mg}$ of dry weight) } \\
\hline & & & & Soluble & Insoluble \\
\hline $\mathrm{NaCl}(0.9 \%)$ & $2.2 \pm 0.5^{a}$ & $405.5 \pm 152.2^{a}$ & $2630 \pm 2280^{a}$ & $16.5 \pm 4.3^{\mathrm{ab}}$ & $109.6 \pm 32.4^{a}$ \\
\hline $\mathrm{CHX}(0.12 \%)$ & $1.0 \pm 0.3^{b}$ & $328.2 \pm 275.8^{a}$ & $2.23 \pm 2.0^{b}$ & $19.7 \pm 4.3^{a}$ & $44.9 \pm 16.8^{b}$ \\
\hline $\mathrm{NaF}(0.05 \%)$ & $2.0 \pm 0.4^{a}$ & $348.0 \pm 135.9^{a}$ & $1810 \pm 1280^{a}$ & $12.7 \pm 3.4^{b}$ & $100.6 \pm 44.7^{a}$ \\
\hline $\mathrm{Fe}(1.0 \mu \mathrm{g} / \mathrm{mL})$ & $2.0 \pm 0.2^{a}$ & $293.7 \pm 130.3^{a}$ & $3360 \pm 2650^{a}$ & $14.8 \pm 3.8^{\mathrm{ab}}$ & $79.3 \pm 39.6^{a b}$ \\
\hline $\mathrm{Fe}(10.0 \mu \mathrm{g} / \mathrm{mL})$ & $1.8 \pm 0.4^{a}$ & $355.8 \pm 221.8^{a}$ & $2290 \pm 1980^{\circ}$ & $14.2 \pm 4.2^{\mathrm{b}}$ & $93.6 \pm 24.1^{\mathrm{ab}}$ \\
\hline $\mathrm{Fe}(100.0 \mu \mathrm{g} / \mathrm{mL})$ & $2.0 \pm 0.5^{a}$ & $258.9 \pm 145.2^{a}$ & $760 \pm 560^{a}$ & $13.1 \pm 4.2^{b}$ & $83.7 \pm 21.8^{a b}$ \\
\hline
\end{tabular}

Treatments followed by distinct letters differ statistically $(p<0.05)$. CHX: chlorhexidine digluconate. EPS: extracellular polysaccharides.

$\%$ SHL value when compared with the negative control group $(\mathrm{p}<0.05)$, but it did not differ from the positive controls used ( $\mathrm{CHX}$ and $\mathrm{NaF}$ ) (Figure 2). Fe concentrations less than $100 \mu \mathrm{g} / \mathrm{mL}$ did not reduce the \%SHL (Tukey's test); however, a significant inverse dose-response effect was found for the relationship between $\mathrm{Fe}$ concentration and \%SHL as well as for reduction of biofilm bacterial viability (Table 2).

\section{Discussion}

It is challenging to control diseases caused by biofilms due to the difficulty in finding substances able to interfere with factors involved with bacterial organization in a biofilm as well as the antibacterial properties of the biofilm structure itself. Fe ions affect the enzymes responsible for bacterial adhesion to dental biofilms and bacterial metabolism, and this combination of effects may be responsible for the anticaries effect.
The results of this study show a dose-response relationship between Fe concentration and reduction in enamel demineralization (Table 2). At a concentration of $100 \mu \mathrm{g} / \mathrm{mL}$, the effect of Fe on reduction of demineralization was similar to that of $0.12 \% \mathrm{CHX}$ and $0.05 \% \mathrm{NaF}$ (Table 1). Our results also show a dose-response relationship between $\mathrm{Fe}$ concentration and reduction of viable bacteria in the biofilm (Table 2), though only the effect of CHX was significant on $S$. mutans reduction when compared to the negative control (Table 1). On the other hand, we did not observe a dose-response relationship for the EPSs (Table 2), for which only CHX had a significant effect on reducing IEPS when compared to the negative control (Table 1).

The present results showing that $\mathrm{Fe}$ reduces enamel demineralization at the highest concentration tested $(100 \mu \mathrm{g} / \mathrm{mL})$ corroborate previous results obtained in rats ${ }^{5,6}$ and in situ. ${ }^{7}$ On the other hand, the mechanism for this effect does not seem to be 
Figure 2 - Means $(n=9)$ of the percentage of enamel surface hardness loss (\%SHL) according to the treatments. (The bars show the standard deviation, and the capital letters show the statistical difference).

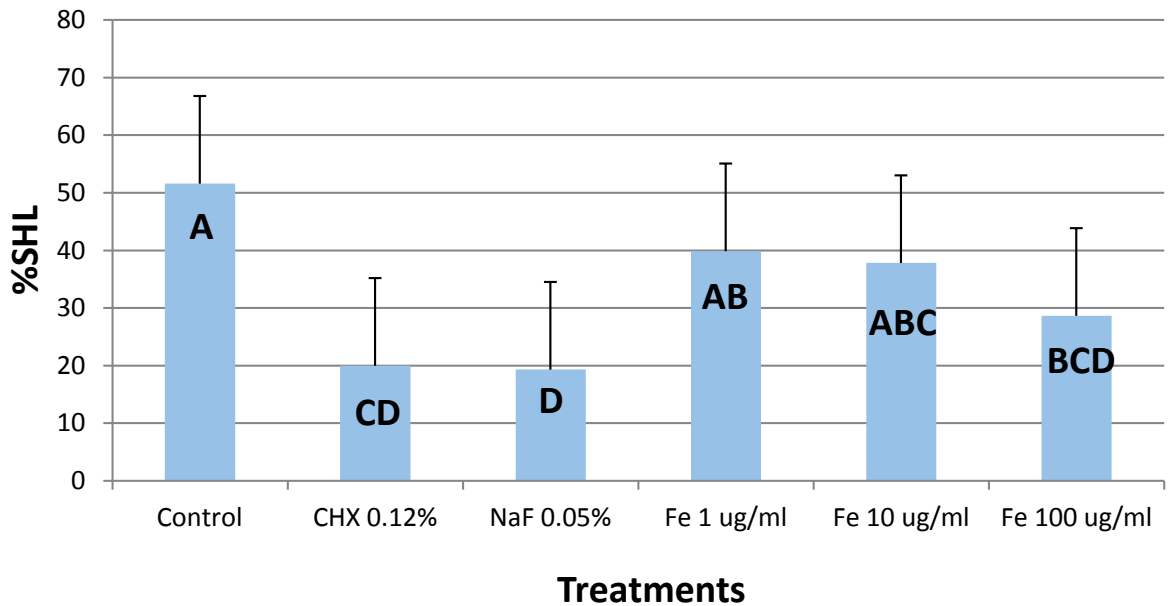

Table 2 - Correlation ( $r$ ) and significance $(p)$ between the Fe concentration $(0-100 \mu \mathrm{g} / \mathrm{mL})$ and its effect on biofilm and enamel demineralization $(\mathrm{n}=9)$.

\begin{tabular}{c|c|c}
\hline Response variable & $r$ & $p$ \\
\hline Viable bacteria & -0.34 & 0.04 \\
\hline Dry weight & -0.24 & 0.158 \\
\hline IEPS & -0.21 & 0.213 \\
\hline$\%$ SHL & -0.46 & 0.005 \\
\hline
\end{tabular}

IEPS: Insoluble extracellular polysaccharides. \%SHL: percentage of enamel surface hardness loss

related to inhibition of EPS production by $S$. mutans GTFs. ${ }^{12,13}$ Like prior in situ dental biofilm findings, ${ }^{7}$ our results suggest that the reduction in demineralization cannot be explained by a direct effect on GTF activity. This absence of an effect on EPS production by $S$. mutans in the biofilm also cannot be explained based on the concentration of Fe used in this experiment, since at the highest concentration used $(100 \mu \mathrm{g} / \mathrm{mL}=1.8 \mathrm{mM}), 80 \%$ EPS inhibition, found in previous in vitro studies, ${ }^{13}$ would have been expected. The lack of EPS inhibition suggests that reduction in demineralization cannot be explained by a specific oxidative effect via the Fenton reaction in the amino acid residues of the active site of GTFs, as Devulapall and Mooser ${ }^{13}$ have suggested.

In fact, in the Fenton reaction, Fe reacts with $\mathrm{H}_{2} \mathrm{O}_{2}$ to form a hydroxyl radical $(\mathrm{OH} \cdot)$, which is a nonspecific oxidizing agent that provokes irreversible changes in all proteins. Thus, the antibacterial effect would not be specific; and in this study, an Fe dose-dependent effect was observed in the reduction of viable bacteria in the $S$. mutans biofilm (Table 1). These results are in line with the findings of Dunning et al., ${ }^{8}$ who showed an Fe dose-dependent effect from 0 to $10 \mathrm{mM} \mathrm{Fe}$ in reducing the number of planktonic cells of $S$. mutans. Although by ANOVA we did not find Fe treatments to have an effect on viable $S$. mutans cells compared with the negative control group, regression analysis and the trend observed in our findings support the results of Pecharki et al., ${ }^{7}$ who showed in situ that $\mathrm{Fe}$ at concentration of $100 \mu \mathrm{g} / \mathrm{mL}$ was able to reduce the number of viable $S$. mutans cells present in dental biofilm.

Enamel demineralization effects, such as those observed in this study, could potentially be due to a decrease in the solubility of the enamel in an acidic solution. Such a mechanism was proposed long ago $^{19}$ and has been revisited recently. ${ }^{20}$ However, this explanation does not fit with the current study because, in our protocol, the Fe treatment was applied to the biofilm on the enamel not to the surface of the enamel itself. Therefore, it can be deduced that the effect observed can be attributed to actions of Fe within the biofilm. ${ }^{7}$ On the other hand, in this study, $0.05 \% \mathrm{NaF}$ also reduced enamel demineralization without having any effect on the biofilm formed. In addition, the physiochemical effect of fluoride on the process of developing caries lesions, reducing demineralization, and activating remineralization of the enamel, is well known. ${ }^{21}$ In fact, fluoride at the concentration used did not inhibit the ability of the $S$. mutans biofilm to transform sucrose 
into acids (Figure 1), confirming our previous study in which this study model was validated. ${ }^{15}$

\section{Conclusion}

In conclusion, the present findings suggest that the anticaries mechanism of Fe may not involve the direct oxidative inhibition of GTF enzymes.

\section{References}

1. Fejerskov $\mathrm{O}$. Changing paradigms in concepts on dental caries: consequences for oral health care. Caries Res. 2004 MayJun;38(3):182-91. Review.

2. Hamada S, Koga T, Ooshima T. Virulence factors of Streptococcus mutans and dental caries prevention. J Dent Res. 1984 Mar;63(3):407-11.

3. Paes Leme AF, Koo H, Bellato CM, Bedi G, Cury JA. The role of sucrose in cariogenic dental biofilm formation--new insight. J Dent Res. 2006 Oct;85(10):878-87. Review

4. World Health Organization. The World Health Report 2002: reducing risks, promoting healthy life. Geneva: WHO; 2002.

5. Emilson CG, Krasse B. The effect of iron salts on experimental dental caries in the hamster. Arch Oral Biol. 1972 Oct;17(10):1439-43.

6. Miguel JC, Bowen WH, Pearson SK. Effects of iron salts in sucrose on dental caries and plaque in rats. Arch Oral Biol. 1997 May;42(5):377-83.

7. Pecharki GD, Cury JA, Paes Leme AF, Tabchoury CPM, Del Bel Cury AA, Rosalen PL, et al. Effect of sucrose containing iron (II) on dental Biofilm and enamel demineralization in situ. Caries Res. 2005 Mar-Apr;39(2):123-9.

8. Dunning JC, Ma Y, Marquis RE. Anaerobic killing of oral streptococci by reduced transition metal cations. Appl Environ Microbiol. 1998 Jan;64(1):27-33.

9. Berlutti F, Ajello M, Bosso P, Morea C, Petrucca A, Antonini G, et al. Both lactoferrin and iron influence aggregation and biofilm formation in Streptococcus mutans. Biometals. 2004 Jun;17(3):271-8.

10. Rosalen PL, Pearson SK, Bowen WH. Effects of copper, iron and fluoride cocrystallized with sugar on caries development and acid formation in desalivated rats. Arch Oral Biol. 1996 Nov;41(11):1003-10.

\section{Acknowledgments}

This study received financial support from CAPES (PROCAD-251/2007) and from FAPEMA that supported the English reviewing of this manuscript. The authors thank Tamires Munerato, technician of the Oral Biochemistry Laboratory, Piracicaba Dental School, for her help with the laboratory analyses.

11. Bowen WH, Koo H. Biology of Streptococcus mutans-Derived Glucosyltransferases: Role in Extracellular Matrix Formation of Cariogenic Biofilms. Caries Res. 2011Apr;45(1):69-86.

12. Wunder D, Bowen WH. Action of agents on glicosyltransferases from Streptococcus mutansin solution and adsorbed to experimental pellicle. Arch Oral Biol. 1999 Mar;44(3):203-14.

13. Devulapalle KS, Mooser G. Glucosyltransferase inactivation reduces dental caries. J Dent Res. 2001 Feb;80(2):466-9.

14. Koo H, Hayacibara MF, Schobel BD, Cury JA, Rosalen PL, Park YK. Inhibition of Streptococcus mutans Biofilm accumulation and polysaccharide production by apigenin and ttfarnesol. J Antimicrob Chemother. 2003 Nov;52(5):782-9.

15. Ccahuana-Vásquez RA, Cury JA. S.mutans biofilm model to evaluate antimicrobial substances and enamel demineralization. Braz Oral Res. 2010 Apr-Jun;24(2):135-41.

16. Aires CP, Del Bel Cury AA, Tenuta LMA, Klein M, Koo $\mathrm{H}$, Duarte S. Effect of sucrose and starch on dental Biofilm formation and on dentin demineralization. Caries Res. 2008;42(5):380-6.

17. Cury JA, Rebelo MA, Del Bel Cury AA, Derbyshire MT, Tabchoury CP. Biochemical composition and cariogenicity of dental plaque formed in the presence of sucrose or glucose and fructose. Caries Res. 2000 Nov-Dec;34(6):491-7.

18. Box GEP, Hunter JS, Hunter WG. Statistics for experimenters: design, innovation, and discovery. 2nd ed. New York: John Wiley and Sons; 2005. 664 p.

19. Manly RS, Bibby BG. Substances capable of decreasing the acid solubility of tooth enamel. J Dent Res. 1949 Apr;28(2):160-71.

20. Alves KM, Franco KS, Sassaki KT, Buzalaf MA, Delbem AC. Effect of iron on enamel demineralization and remineralization in vitro. Arch Oral Biol. 2011 Nov;56(11):1192-8.

21. Tenuta LMA, Cury JA. Fluoride: Its role in Dentistry. Braz Oral Res. 2010;24 Spec Iss 1:9-17. 